\title{
A INVISIBILIDADE DOS TRANSEXUAIS NA EDUCACCÃO: ANÁLISE DOS DISCURSOS LEGAIS SOBRE O NOME SOCIAL NAS ESCOLAS DO BRASIL
}

\section{THE INVISIBILITY OF TRANSSEXUALS ON EDUCATION: ANALYSIS OF DISCOURSE LEGAL ON SOCIAL NAME IN THE SCHOOL OF BRAZIL}

\begin{abstract}
Patrícia Lessa ${ }^{48}$ Marcio Oliveira ${ }^{49}$

\section{Resumo}

O processo de transexualização ainda é uma discussão recente no Brasil, pouco ou nada se fala sobre as/os transexuais. Sua invisibilidade nos espaços educacionais é notável. Este estudo objetiva analisar os discursos do Conselho Federal de Medicina (CFM) confrontando-os com os discursos da recente legislação do "nome social" que está em vigor nas escolas públicas brasileiras. Como procedimento de coleta de dados, usamos o método documental. Os saberes tecnobiomédicos e jurídicos identificam na cirurgia de correção da genitália formas de normalização dos corpos. A transexualidade apresenta-se como uma interrogação radical não somente sobre os processos de identificação, mas, também, sobre a noção de identidade sexual. A desconstrução de gênero se faz presente mesmo na tentativa de enquadrá-la às normas e ditames da heteronormatividade. Daí decorre a importância desse estudo para educação.
\end{abstract}

Palavras-Chave: Transexuais. Educação. Brasil. Legislação.

\begin{abstract}
The process is still transexualization a recent discussion in Brazil, little or nothing is said about the / transsexuals. Their invisibility in educational spaces is remarkable. This study aims to analyze the medical discourses of the Federal Council of Medicine (CFM) by confronting them with the speeches of recent legislation the "name" is taking place in public schools. As data collection procedure, we use the documentary method. Tecnobiomedical knowledge and identify legal for surgical repair of the genitalia forms of standardization bodies. Transsexualism is presented as a radical question not only about the processes of identification, but also about the notion of sexual identity. The deconstruction of gender is present even in trying to fit it to the norms and dictates of heteronormativity. Hence the importance of this study for education.
\end{abstract}

Keywords: Transsexuals. Education. Brazil. Legislation.

48 Professora do Departamento de Fundamentos da Educação Universidade Estadual de Maringá (UEM/PR), Pós-Doutorado em Letras, na área de Estudos da Linguagem, na Universidade Federal Fluminense (UFF/RJ) supervisão do Dr. Sebastião Votre. Formada em Educação Física pela Universidade Federal de Pelotas (UFPel/RS), Doutora na área de Estudos Feministas e de Gênero pelo Programa de Pós-Graduação em História (UnB/DF), Mestrado em Filosofia da Educação (UNICAMP). Autora do livro: "Mulheres à Venda", editado pela EDUEL, lançado em 2005 e colaboradora em outros livros com o mesmo tema. Coordenadora do Grupo de Estudos em Pedagogias do Corpo e da Sexualidade (GEPECOS). E-Mail: mafalda_cat@yahoo.com.br.

49 Professor Marcio Oliveira, graduado em Pedagogia pela Universidade Estadual de Maringá, participa do Grupo de Estudos em Pedagogias do Corpo e da Sexualidade (GEPECOS). Realiza disciplinas no Mestrado em Educação da Universidade Estadual de Maringá. E-Mail: marcio.1808@ hotmail.com. 


\section{Notas introdutórias para uma gramática transexual}

De acordo com a gramática quando existe pelo menos um elemento masculino o gênero predominante é o masculino. Teóricas/os feministas buscam resolver esse impasse utilizando-se de recursos como os símbolos: @, *, ou mesmo, o/a. Quando se trata da transexualidade a problemática agrava-se: como devemos nos referir a uma mulher transexual que é biologicamente homem? Ou um homem transexual que tem no registro civil um nome feminino? As definições sociais, médicas e legais ainda caminham a passos lentos na resolução dessa questão, sendo assim a gramática ainda é a instância menos questionada. Com a recente legislação do "nome social" no Brasil essa questão tende a ganhar contornos problematizadores.

A lei do nome social assegura que a utilização do nome escolhido por transexuais e travestis deve ser respeitada no momento em que os mesmos requerem alguns documentos públicos. Entende-se aqui como nome social o nome pelo qual travestis e transexuais se identificam e são identificadas/ os pelos seus pares. Santos (2010) ao narrar experiências de transexuais, que subvertem as normas de gênero na escola, afirma que o nome é potencializado como algo muito caro. A autora problematiza o nome como uma escolha, algumas vezes pessoal, outras vezes como indicação dos mais velhos/ as, de uma transexual ou travesti mais velha no grupo, de uma líder. O importante é o significado do nome como parte de uma construção da identidade fabricada, sua identificação materializada na construção do corpo. O nome social é geralmente apontado como reconhecimento e respeito à construção corporal assumida pelo/a transexual. Como o processo de construção corporal via cirurgia e tratamento hormonal geralmente é demorado, exigindo no mínimo dois anos de tratamento psicológico antes que a cirurgia seja liberada, a construção do visual precede a construção corporal. O/a transexual passa a trajar-se tal como se percebe subjetivamente, indo na contramão de sua identidade civil, o que em muitos casos gera constrangimento social, pois o nome não condiz com o que se mostra socialmente (ARÁN, 2006).

Caso recente foi divulgado na mídia: a travesti Penélope Reis foi barrada na seção eleitoral onde iria votar no município de Raimundo Nonato, no Piauí. Com apoio de sua mãe ela foi à delegacia e registrou a ocorrência, ingressando com uma ação judicial por danos morais contra o mesário e o promotor. A matéria que foi divulgada na mídia é ofensiva a Penélope e coaduna com o enquadramento de gênero, pois o tratamento continua no masculino sendo que a identidade assumida é feminina. Diz o repórter do jornal estadão: "O estudante [...] foi barrado na $62^{a}$ seção eleitoral, da $95^{\mathrm{a}}$ zona eleitoral, porque não conferia a pessoa, que é travesti, com a foto apresentada no documento" (COELHO, 2010, web). A sociedade heteronormativa não respeita o direito da pessoa em assumir a identidade de gênero oposta ao biológico, tal como o repórter que, mesmo ao documentar um delito insiste em manter a identidade da vitima no masculino.

Em função desse constrangimento social é que a lei foi criada. A lei 
foi foco de várias notícias e reportagens, antes e depois de sua publicação. Segundo Santos (2010, p. 162) o nome social foi adotado em onze estados brasileiros como uma política afirmativa. Após a redação da dissertação de Dayana Santos (2010) a legislação do nome social foi aprovada em mais dois estados brasileiros, subindo para 13 estados.

A importância deste estudo se justifica pela necessidade de entender os mecanismos legais e institucionais usados na promoção de direitos para populações específicas historicamente marginalizadas. O estado do Paraná, em 2010, foi o terceiro no Brasil a incluir a legislação do nome social no contexto escolar através do registro nos documentos escolares por meio de medida administrativa da Secretaria Estadual de Educação (PARANÁ, 2010a; PARANÁ, 2010b; PARANÁ, 2010c). O nome social deve ser entendido como produtor de significado que institui valores, crenças e regras no interior da prática docente. Embora as leis não atuem diretamente nas práticas, elas as reorganizam e redistribuem, formando novas configurações sociais.

Esta pesquisa caracteriza-se como estudo documental. Para analisarmos os documentos usamos os procedimentos metodológicos da análise retórica. Perelman (1996, p. 297) nos diz que os argumentos que fundam a estrutura do real são aqueles que "generalizam aquilo que é aceito a propósito de um caso particular (ser, acontecimento, relação) ou transpõem para outro domínio o que é admitido num domínio determinado". Trata-se dos argumentos que se utilizam do exemplo, do modelo, da analogia e da metáfora. Em nosso estudo vamos recorrer aos exemplos que são fonte e estratégia de debates nos fóruns sobre sexualidade e diversidade na educação. Os documentos compilados para analise são: o Decreto n. ${ }^{\circ} 5.397$ de 22 de março de 2005, a Portaria n. ${ }^{\circ} 1.707$ de 19 de agosto de 2008, a Resolução n. ${ }^{\circ}$ 1.955/2010 de 03 de setembro de 2010, a Instrução Conjunta nº 02/2010 PR de 20 de maio de 2010, a Orientação Pedagógica n. ${ }^{\circ}$ 01/2010 - PR de 08 de novembro de 2010, e o Parecer CP/CEE n. ${ }^{\circ} 01 / 2009$ - PR de 08 de outubro de 2009.

O trabalho contém duas partes: na primeira apresentamos as discussões sobre as negociações tensas que envolvem o reconhecimento do corpo, da identidade e do nome como constructos subjetivos amparados pelo direito ao respeito e à liberdade de expressão. Na segunda parte apresentamos as discussões que envolveram a proposta do nome social nas escolas do Paraná, bem como, a reverberação em leis com afinidades temáticas.

\section{Nome social ou "o direito de ser quem sou"}

A ideia para esse subtítulo surgiu da campanha: "Sou Travesti, tenho direito de ser quem sou", lançada pelo Governo Federal juntamente com representantes do movimento de travestis em abril de 2010. O direito ao uso do nome social é conquista recente, fruto de longa batalha. Tanto a Organização Mundial de Saúde (OMS) como as organizações de ativistas transexuais e travestis são unânimes em afirmar que o nome civil, aquele registrado nos 
documentos legais, muitas vezes é usado para causar constrangimento em determinados espaços públicos. Essa tem sido considerada a principal causa de evasão escolar e do afastamento dessa população dos serviços públicos (BIANCARELLI, 2010).

O direito ao uso do nome social ainda está restrito às escolas e a alguns serviços públicos de saúde. Alterar o nome civil demanda uma iniciativa individual através de ações judiciais. Um dos exemplos mais conhecidos no Brasil foi do caso Roberta Close. Ela fez a cirurgia no ano de 1989 fora do Brasil e, no ano seguinte, entrou com ação judicial na cidade do Rio de Janeiro para mudar o nome de registro. Ganhou na primeira instância, porém, a promotoria não recorrev e em 1997 o Superior Tribunal Federal reformulou a sentença e negou o direito a mudança de nome. Nesse período de tramitação do processo judicial Roberta foi barrada em um aeroporto internacional, pois, sua aparência já não condizia com os dados do documento, levando o caso a imprensa internacional. Foi somente no dia 4 de março de 2005 que saiu a sentença favorável a mudança na certidão de nascimento, e ela passou a ser reconhecida civilmente como Roberta Gambine Moreira, do "sexo feminino". Esse caso é exemplar para uma análise critica da legislação, pois foram necessários 15 anos desde a cirurgia até a mudança do nome, sendo que a mudança física já indica uma nova relação com o corpo e o gênero (BIANCARELLI, 2010).

As discussões legais caminham para o reconhecimento da importância da troca de nome antes da cirurgia, pois esse é um recurso legal que garante aos sujeitos uma nova identificação, uma readequação para o pertencimento de gênero. Além disso, o/a travesti não investe em mudanças cirúrgicas, embora em alguns casos utilize os recursos hormonais e o silicone, mas se utiliza de outros recursos para garantir o pertencimento ao gênero desejado, como vestuário e acessórios aceitos socialmente para o gênero pretendido.

Uma informação importante é que o nome social poderá ser usado somente nos documentos internos das instituições de ensino, ou seja, nas listas de chamadas, matrículas, crachás e na sala de aula. Para que haja a inserção do nome social em históricos escolares, bem como nos demais documentos, é necessária a mudança do nome civil junto a uma ação judicial individual (LEITÓLES, 2010). Uma das questões que chama a atenção é justamente o isolamento que a situação causa. Cada caso isolado deixa a impressão de uma conquista social. É uma conquista, porém, individual. Assim tivemos o exemplo do caso de Roberta Close que levou 15 anos para alcançar o direito a mudança do nome civil, quando o seu corpo já estava readequado para o gênero feminino. Durante esse tempo ela viveu com corpo e trajes femininos, porém com os documentos e com identificação masculina, ou seja, o registro do gênero/sexo não condizente com sua aparência. Não se trata somente de uma mudança de sexo ou de "opção", mas uma necessária adequação tanto do nome como do gênero, a fim de minimizar os constrangimentos. 
Alexandre Santos, conhecido como Xande, um transexual masculino foi o primeiro caso de homem transexual dirigindo uma entidade mista: a Associação da Parada do Orgulho LGBT (lesbianas, gays, bissexuais e transexuais) de São Paulo (BIANCARELLI, 2010). Ele apontou que no caso da transexualidade masculina os desafios e as dificuldades são maiores. Vivemos em um mundo misógino que valoriza os atributos masculinos em detrimento dos femininos, por isso, existe uma maior resistência em ingressar nesse universo feminino, ou seja, fazer a passagem de mulher para homem. Diferentemente da transexualidade feminina em que já temos referencias midiáticas, a transexualidade masculina permanece obscura. A legislação, além disso, está em atraso com relação aos casos de transexualidade feminina, como são os exemplos da inserção de mulheres transexuais nas olimpíadas. Trata-se de conquista ainda improvável para as transexuais masculinas.

Uma das reivindicações era o direito a histerectomia e mastectomia, retirada do útero e ovário e das mamas respectivamente, pois o Sistema Único de Saúde (SUS) ainda o considerava uma cirurgia experimental, muito embora sejam cirurgias corriqueiras para as mulheres vitimas de câncer. Assim sendo, os transexuais masculinos consideravam esse impedimento muito mais relacionado às discriminações de gênero do que propriamente um problema de saúde pública. Na entrevista, concedida a Aureliano Biancarelli, disse Alexandre: "Ninguém vai saber o que tenho dentro da calça, posso até conviver com uma prótese, mas um homem carregar um peito e ter menstruação é uma anormalidade que fere meus direitos" (BIANCARELLI, 2010, p. 43).

No dia 03 de setembro de 2010 o Conselho Federal de Medicina (CFM) publicou no Diário Oficial da União uma nova resolução sobre a assistência a transexuais masculinos no Brasil, a resolução no 1.955/2010, que delibera sobre os procedimentos para retirada de mamas, ovários e útero (CFM, 2010). Com a mudança esses procedimentos cirúrgicos não são mais considerados experimentais e podem ser realizados em hospitais públicos ou privados que sigam as recomendações do Conselho. A cirurgia e o tratamento para construção do pênis, denominada neofaloplastia, não foi liberada com essa resolução, permanecendo ainda experimental.

Os discursos legais embora sejam divulgados na mídia como inovadores, são carregados pela marca do estigma e da exclusão social. A invisibilidade social causa grandes danos os sujeitos envolvidos. Para serem sujeitos plenos de direito, transexuais e travestis reivindicam que o nome acompanhe as mudanças físicas, pois se torna problemático, na sociedade brasileira atual, conviver em um corpo feminino com nome masculino e identidade de gênero masculino nos documentos oficiais ou vice-versa. Esse descompasso na legislação é grande, pois como vemos o processo transexualizador começou a adquirir novos contornos com a portaria 1.707 do Ministério da Saúde. Em agosto de 2008 a citada portaria instituiu para o SUS um conjunto de estratégias para transexuais que pretendem realizar modificações corporais do sexo, em função de um sentimento de desacordo entre sexo biológico e gênero (Ministério da Saúde, 2010). Somente dois anos após essa medida 
vemos a lei do nome social entrar na ordem do dia no Brasil.

Essa reivindicação ao direito do uso do nome social está em consonância com algumas das premissas básicas dos direitos humanos: o direito a existência, ao respeito, direito de ser quem se é. Pensar em leis e direitos é pensar nos pressupostos dos direitos humanos:

\begin{abstract}
Pensar em direitos humanos é pensar na constituição de preceitos e concepções que nos permitam compreender que, independentemente de origem, credo, cor da pele, orientação sexual, faixa etária e classe social, todos os sujeitos - respeitadas as diferenças culturais, sociais, histórias etc. - numa sociedade como a nossa são passíveis de direitos e deveres (SANTOS; ARAUJO, 2009, p. 22).
\end{abstract}

Nem todos os discursos que aparecem nas leis são colocados em prática. E na escola não é diferente. "[...] nem sempre a prática de cumprimento ao que precede as legislações acerca dos direitos humanos se faz vigente na escola" (SANTOS; ARAUJO, 2009, p. 22). Será por isso que vemos poucos travestis e transexuais nos bancos escolares e nas universidades? Quando um transexual ascende à carreira universitária é logo midiatizado, porquê? O acesso à educação não faz parte dos direitos humanos, garantido em nossa Constituição?

Ao ler a Constituição Federal de 1988 perceberemos que não há menção alguma relacionada à discriminação quanto à orientação sexual, porém, em dois de seus artigos (terceiro e quinto artigo) é tratada a igualdade de direitos que abrange todos os seres humanos:

Art. $3^{\circ}$ - Constituem objetivos fundamentais da República Federativa do Brasil:

IV - promover o bem de todos, sem preconceitos de origem, raça, sexo, cor, idade e quaisquer outras formas de discriminação.

Art. $5^{\circ}$ - Todos são iguais perante a lei, sem distinção de qualquer natureza, garantindo-se aos brasileiros e aos estrangeiros residentes no País a inviolabilidade do direito à vida, à liberdade, â igualdade, à segurança e à propriedade (BRASIL, 1990).

Apesar da importância da lei do nome social, a sua entrada no espaço escolar provavelmente não irá acontecer sem resistências; as iniciativas legais foram começaram em 2010; fruto de anos de batalhas e militância, essa lei chegou às escolas brasileiras em 2010. É, portanto, muito recente. É importante destacar que as militâncias LGBT estão atentas à necessidade de reavivar um sentimento de que a educação pode servir como instrumento de mudança social. A escola tem o papel social de ensinar as crianças a respeitar seus colegas, sejam eles travestis ou transexuais, contribuindo assim para que uma nova relação se estabeleça entre as pessoas. A diferença é sempre suspeita, pois ela desafia a homogeneidade social e, em consequência, aqueles que exercem o poder, sobretudo de forma tirânica. 


\section{Educação para a diversidade, conquistas ou ilusões? Um olhar sobre a SEED-PR}

Devemos pensar as instituições escolares como lócus de formação de pessoas. Pessoas que criam suas identidades, também, durante o período escolar. Logo, esta instituição deve ser alvo de ações que minimizam forma de preconceito, seja étnico-racial, gênero e/ou orientação sexual (Louro, 2001). No Paraná, sob pressão dos movimentos sociais e em função do avanço dos debates em torno da nova política educacional do Estado foi criado em 2007 o Departamento da Diversidade (DEDI). Em 2009 o lugar institucional para o direcionamento da política pública educacional em gênero e diversidade sexual foi denominado Núcleo de Gênero e Diversidade Sexual (NGDS) alocado no DEDI.

O NGDS foi criado a partir de um compromisso com os sujeitos das relações entre os gêneros e das diversas identidades sexuais que têm se organizado historicamente como movimentos sociais em busca de igualdade de direitos na educação. Delineiam-se nesse contexto ações voltadas para assunção dos compromissos com a comunidade LGBT.

A criação do NGDS foi importante para evidenciar institucionalmente que a discriminação e o preconceito são fatores determinantes nos baixos índices de desempenho escolar e na evasão do espaço escolar de lésbicas, gays, travestis e transexuais, negros e negras. Freire, Santos e Haddad (2009, p. 9) afirmam que: "as discriminações de gênero, étnico-racial e por orientação sexual, como também a violência homofóbica são produzidas e reproduzidas em todos os espaços da vida social brasileira. A escola, infelizmente, é um deles".

Pensando nessas e em outras questões o NGDS propôs determinadas ações, como cursos de formação continuada para professores/as, grupos de estudos, elaboração de materiais didáticos, elaboração de vídeos e outros materiais para direcioná-los ao espaço escolar. Tais estruturas foram criadas para enfrentar as idéias de padrões hegemônicos no que diz respeito às identidades sexuais e de gênero. Berkins (2009, p. 99) afirma que "É fato observado que na escola se aprende a diferença, e que historicamente a escola trata de colocar para fora sujeitos que resistem à normatização de suas identidades sexuais e de gênero a partir de padrões hegemônicos".

As iniciativas alavancaram a temática da sexualidade nos espaços escolares buscando atender as demandas dos movimentos sociais e minimizar os efeitos deletérios das discriminações de gênero na educação, fazendo ressonâncias na saúde. O NGDS buscou fortalecer a parceria com a Secretaria de Estado da Saúde promovendo cursos de multiplicadores em educação para diversidade, construindo planos de ação para as escolas. Assim, com uma atuação massiva o órgão administrativo assume alguns compromissos, dentre eles;

o princípio do reconhecimento, respeito e apoio à presença da diversidade sexual nas escolas em detrimento 
de uma postura de tolerância que pressupõe uma hierarquização dos sujeitos, freqüentemente adotada na ótica da manutenção da ordem social vigente onde alguns sujeitos possuem maior valor que outros (BELLO; LUZZI, 2009, CD-ROM).

No estado do Paraná as ações voltadas ao público LGBT se intensificaram a partir do ano de 2007. Neste ano houve a reestruturação da SEED concomitante com a criação do Departamento da Diversidade, que abrigava a equipe que trabalhava com a sexualidade e a prevenção de drogas. Em 2008, percebeu-se que os dois temas não poderiam caminhar juntos. Essa equipe, então, foi transferida para a Diretoria de Políticas e Programas Educacionais sob a Coordenação dos Desafios Educacionais Contemporâneos. Nesta mesma época, a equipe foi separada, constituindo então uma equipe de Sexualidade e outra de Prevenção ao uso de Drogas (BELLO; LUZZI, 2009, CD-ROM).

Ao se constituir a equipe de Sexualidade, esse grupo passou a trabalhar com enfoque "na produção de materiais de apoio pedagógico e na formação continuada das/dos profissionais da educação" (BELLO; LUZZI, 2009, CD-ROM). No ano de 2009, em uma nova reestruturação essa equipe foi inserida no DEDI. O grupo percebeu a necessidade de inclusão social dos sujeitos que compõem a classe LGBT,

\begin{abstract}
Esse redirecionamento incluiu de forma mais expressiva a discussão sobre as relações entre os gêneros e da diversidade sexual nas políticas públicas educacionais reconhecendo os sujeitos das relações entre os gêneros e da diversidade sexual como sujeitos de classe, com direitos civis e sociais, que precisam ser garantidos nos espaços escolares. Essa postura político-pedagógica determinou a definição do Núcleo de Gênero e Diversidade Sexual NGDS (BELLO; LUZZI, 2009, CD-ROM).
\end{abstract}

Dentro do NGDS várias são as ações voltadas para atender as demandas da comunidade LGBT. Dentre as ações que procuram minimizar as formas de preconceito e enfrentamento das diferenças de gênero estão a construção dos referenciais que norteiam as "discussões do núcleo são de classe, gênero, raça/etnia e diversidade sexual" (BELLO; LUZZI, 2009, CD -ROM).

Tais ações são orientadas por meio da articulação de três eixos principais de trabalho. O primeiro remete à "Prevenção e Promoção da Saúde", que aborda a prevenção à gravidez na adolescência e a transmissão de doenças sexualmente transmissíveis; o segundo eixo está ligado ao gênero e luta para desnaturalizar as relações de poder quanto à diferença, bem como acabar com a invisibilidade das mulheres como sujeitos históricos; o terceiro eixo trabalha com a diversidade sexual, abordando os direitos civis e sociais de todos e de todas, as ações preconceituosas e a discriminação contra pessoas cujas suas identidades sexuais não são hegemônicas (BELLO; LUZZI, 2009, CD-ROM). Os eixos são trabalhados em cursos de capacitação 
e formação continuada, por meio de produção de materiais didáticos. 0 NGDS buscou desenvolver atividades com os/as profissionais da educação:

Temos como desafio provocar as/os diferentes sujeitos da escola a perceber, questionar e interpretar por meio de conhecimentos específicos as relações de preconceito existentes no seu interior e na sociedade e construir coletivamente encaminhamentos metodológicos para essas questões (BELLO; LUZZI, 2009, CD-ROM).

Em 28 de novembro de 2007 foi assinado um Decreto Federal que convocou a primeira Conferência Nacional de Gays, Lésbicas, Bissexuais, Travestis e Transexuais. No mesmo ano, porém um pouco mais cedo, em 28 de fevereiro, foi assinado um Decreto Estadual, de número 2.228, que convocou a primeira Conferência Estadual GLBT. O motivo primordial de tal conferência foi discutir formas de promover a cidadania desta população historicamente excluída. A temática da conferência foi Direitos Humanos e Políticas Públicas: o caminho para garantir a cidadania de Gays, Lésbicas, Bissexuais, Travestis e Transexuais (PARANÁ, 2010a).

Outro marco que julgamos importante e está descrito no site da SEED é a Portaria n. ${ }^{\circ}$ 4.032, de 24 de novembro de 2005. Esta portaria instituiu um Grupo de Trabalho (GT) cuja função foi de acompanhar a implantação de um programa que garantisse o direito à educação pela população LGBT, entrando em consonância com o Programa Brasil sem Homofobia. Como ação, O GT também procurou promover o respeito à diversidade de orientação sexual e de identidade de gênero nos sistemas educacionais promovendo o debate e levando-o para o interior das escolas (PARANÁ, 2010a).

Em suas falas os/as professores/as deveriam refletir a respeito do preconceito, buscando acabar com essas formas de violação de direito. Segundo Bello e Luzzi (2009, CD-ROM), "ao não enfrentar a reflexão e necessidade de conhecimento sobre a temática acabam [os/as docentes] por referendar a discriminação e a exclusão de inúmeros estudantes do espaço escolar".

A seguir, apontaremos três grandes ações do NGDS que foram realizadas como forma de melhorar a educação no quesito diversidade sexual:

Para abordar as relações entre Gêneros, Diversidade Sexual e relações étnico-raciais de forma integrada a SEED -PR assumiu em parceria com a Universidade Estadual de Ponta Grossa um projeto desenvolvido pela Secretaria Especial de Políticas para as Mulheres - SPM, Secretaria de Promoção da lgualdade Racial - SEPPIR, Ministério da Educação através da SECAD, além do Centro Latino-Americano em Sexualidade e Direitos Humanos - CLAM, do Instituto de Medicina Social da Universidade do Estado do Rio de Janeiro: o Curso Gênero e Diversidade na escola. O curso, com carga horária de 200 horas, sendo 170 a distância e 30 presenciais, atenderá 1.500 professores/as das diversas disciplinas da educação básica da rede pública estadual de ensino. 
O Núcleo também realizou em novembro de 2009 o I Seminário Estadual de Igualdade de Gênero e Diversidade Sexual - em parceria com a SESA, com a Pontifícia Universidade católica do Paraná, com o Núcleo de Estudos de Gênero da UFPR e com a Secretaria de Gênero e Igualdade Racial da APP. Nesse seminário de três dias foi lançado oficialmente o I Caderno Temático de Sexualidade, com a presença dos autores e autoras dessa publicação, numa noite de autógrafos.

Outra importante ação do NGDS se pauta na pesquisa e produção de materiais pedagógicos abordando as temáticas de gênero e diversidade sexual e sua interface com a realidade das escolas públicas da rede estadual de ensino. O I Caderno Temático de Sexualidade terá uma tiragem de 60.000 cadernos para que cada professora e professor da rede receba um exemplar. O caderno conta com textos de fundamentação teórico-metodológica sobre Gênero de Diversidade Sexual e é acompanhado de um DVD com dois vídeos educativos sobre Questões de Gênero na Escola, com a professora Dra. Guacira Lopes Louro, da Universidade Federal do Rio Grande do Sul e Educação Sexual na Escola, com a professora Dra. Jimena Furlani, da Universidade do Estado de Santa Catarina (BELLO; LUZZI, 2009, CD-ROM).

Podemos inferir que as ações da SEED-PR juntamente com o NGDS foram de suma importância para alavancar e discutir temas nas escolas que muitas vezes são esquecidos propositalmente. Realizar cursos de formação continuada, bem como produzir materiais didáticos é fundamental para que se mude a concepção errônea a respeito das identidades sexuais. Porém, não são frequentes as fiscalizações a respeito do uso desses materiais e trabalhos realizados em sala de aula. Além disso, a mudança de governo causa uma quebra na estrutura alcançada ao longo de intenso trabalho. O trabalho foi iniciado, resta-nos saber como as políticas educacionais irão encarar essa legislação e suas repercussões.

\section{Considerações Finais}

O Nome Social é o exemplo de uma lei que chega ao estado do Paraná, e que não é ainda reconhecida nos debates escolares. Pois ainda pode-se perceber que travestis e transexuais são estigmatizados, quando não violentados e assassinados (Gilberti, 2003). O Paraná é considerado um dos Estados com maiores índices de assassinato de travestis e transexuais. Importante ressaltar que nossa sociedade muitas vezes cria meios legais de proteção, mas não meios práticos para sua concretização. Muitas ideias ainda são novas nos espaços escolares. O que é um transexual? O que é um travesti? É igual dizer transgênero? Gilberti (2003, p. 34) aponta uma variação terminológica no seio dos movimentos sociais:

Algunos/as transexuales no operados/as se identifican a si mismos 
como 'transgenderistas'. Más allá de esta variación en la terminología, la mayoría de la gente trans estaría de acuerdo con que su auto identificación es un derecho personal importante, lo cual nosotros apoyamos decididamente.

Devemos entender a lei como forma de minimizar os danos sociais imputados a travestis e transexuais dentro de instituições de ensino. Toni Reis, presidente da ABGLT (Associação Brasileira de Gays, Lésbicas e Transexuais), afirma que "a aprovação do nome social é o primeiro passo para que os travestis e transexuais possam ser incluídos e respeitados nas escolas do Paraná" (LEITÓLES, 2010, web). Sexualidade e diversidade sexual aparecem no discurso das políticas educacionais no contexto nacional quando os dispositivos legais promovem a entrada da temática 'orientação sexual' nos Parâmetros Curriculares Nacionais - PCNs - (BRASIL, 1997; SOUZA, 1997; ALTMAN, 2001).

Os argumentos reunidos nos exemplos citados fluem para a necessidade de leis menos contraditórias, ou seja, para busca de uma regulamentação que compreenda a transexualidade como uma mudança paradigmática, não só sexual, mas do que se entende por ser, existir. Para a quebra dos preconceitos de gênero e todas as formas de enquadramento, que nem sempre funcionam, pois os depoimentos e literatura na área apontam para a pluralidade. Para o respeito às diferenças e entendimento que o ser humano é complexo, portanto, não é passível de generalizações, portanto, não é hegemônico determinado, mas imposto socialmente, portanto passível de ser desconstruído. E por fim que a educação deve assumir o compromisso com a diversidade e o respeito às diferenças, seu compromisso deve ser pautado na efetiva participação dos sujeitos sociais.

A concepção normativa dos sistemas sexo-gênero converte-se em um sistema regulador da sexualidade promovendo ideias cristalizadas cujos reflexos atingem diretamente as populações mais vulneráveis. Entendendo essa problemática é que a ILGA (Associação Internacional de Lésbicas, Gays, Bissexuais, Trans e Intersexo) propôs a Campanha Stop TransPathologization, cujas repercussões irão refletir diretamente na lei do nome social, pois, entre suas reivindicações estão: a retirada do termo "transtorno" dos manuais de doenças, a retirada da menção de sexo nos documentos oficiais, o livre acesso aos tratamentos hormonais e cirúrgicos sem a tutela psiquiátrica e a luta contra a transfobia (ILGA, 2010).

A lei do nome social coloca em cheque a reivindicação pela quebra nas normas de gênero e das identidades fixas. Na gramática normativa do gênero, como diz Arán (2006), o nome é usado tanto para identificar, cristalizar identidades em padrões previamente estabelecidos, mas também para confundir sexo, gênero e práticas sexuais diversas. Uma educação que abrace essa discussão deve ser mais problematizadora do que deliberativa, deve ser mais heterogênea do que hegemônica, enfim, mais preocupada em manter os sujeitos sociais nos bancos escolares. 


\section{Referências}

ALTMAN, H. Orientação Sexual Nos Parâmetros Curriculares Nacionais. Estudos Feministas. Santa Catarina, p. 575-585, 2001.

ARÁN, M. A transexualidade e a gramática normativa do sistema sexo-gênero. Ágora. v.IX, n.1, Rio de Janeiro, jan/jun, p.49-63, 2006.

BELLO, M. C.; LUZZI, J. Gênero e Diversidade Sexual na Escola: da exclusão social à afirmação de direitos. A experiência do Núcleo de Gênero e Diversidade Sexual da Secretaria de Estado da Educação do Paraná. IX Congresso Nacional de Educação. Anais... Curitiba: EDUCERE: PUC, out. 2009.

BERKINS, L. Travestismo, transexualidad y trangeneridad. MONTERO, J (Org.). Um cuerpo mil sexos: intersexualidades. Buenos Aires: Topia editorial, p. 91102. 2010.

BIANCARELLI, A. A Diversidade revelada. São Paulo: Centro de Referência da Diversidade: Ambulatório de Saúde Integral para Travestis e Transexuais, 2010.

FREIRE, N.; SANTOS, E.; HADDAD, F. Construindo uma Política de Educação em Gênero e Diversidade. In Gênero e diversidade na escola: formação de professoras/es em gênero, orientação sexual e relações étnico-raciais. Livro de conteúdo. Versão 2009, Rio de Janeiro: CEPESC: SPM: Brasília, 2009.

GILBERTI, E. Trangéneros: sínteses y aperturas. MAFFÍA, D. Sexualidades migrantes, género y transgénero. Buenos Aires: Feminaria editora, p. 31-58, 2003.

LOURO, G. L. Pedagogia da Sexualidade. In: Louro, G. L. O Corpo educado: pedagogias da sexualidade. 2. ed. Belo Horizonte: Autêntica, 2001.

SANTOS, D. B.; Araujo, D. C. Sexualidades e Gêneros: questões introdutórias. In: PARANÁ. Sexualidade. Curitiba: SEED-PR. 2009.

SANTOS, D. B. Cartografias da transexualidade: a experiência escolar e outras tramas. Dissertação. (Mestrado em educação). Universidade Federal do Paraná, Curitiba, 2010.

SOUZA, P. R. Ao Professor. In: Brasil. Parâmetros curriculares nacionais: pluralidade cultural, orientação sexual / Secretaria de Educação Fundamental. Brasilia: MEC/SEF, 1997.

\section{Fontes documentais}

BRASIL. Parâmetros Curriculares Nacionais: introdução aos parâmetros curriculares nacionais. Secretaria de Educação Fundamental. Brasília: MEC/SEF, 1997. 
. Constituição (1988). Constituição da República Federativa do Brasil:

Promulgada em 5 de outubro de 1988. Juarez de Oliveira (Org). 4 ed. São Paulo: Saraiva, 1990.

Decreto $\mathrm{n}^{\circ} \mathbf{5 . 3 9 7}$ de 22 de março de 2005. Disponível em: <http:// www.planalto.gov.br/ccivil_03/_Ato2004-2006/2005/Decreto/D5397.htm>. Acesso em: ago. 2010.

COELHO, Luciano. Travesti é barrado por mesário e não vota no Piauí. Jornal Estadão, São Paulo, 03 de outubro de 2010. Disponível em: <http://www.estadão.com.br>. Acesso em: dez. 2010.

CONSELHO FEDERAL DE MEDICINA. Resolução $n^{\circ}$ 1.955/2010 de 03 de setembro de 2010. Disponível em:

<http://www.portalmedico.org.br/resolucoes/CFM/2010/1955_2010.htm>. Acesso em: dez. 2010.

LEITÓLES, F. 2010. Nome social nas escolas deverá ser adotado no Paraná nas matrículas para 2010. Disponível em: <http://www.gazetadopovo.com.br/ vidaecidadania/conteudo.phtml + tl=1 \&id=931 681 \& tit=Nome-social-nas-escolas-devera-ser-adotado-no-Parana-nas-matriculas-para-2010>. Outubro, 2009. Acesso em jul. 2010

MINISTÉRIO DA SAÚDE. Portaria $n^{\circ} 1.707 / G M, 19$ de agosto de 2008. Disponivel em: <http://bvsms.saude.gov.br/bvs/saudelegis/gm/2008/ prt1707_18_08_2008.html> Acesso em: dez. 2010.

PARANÁ. Instrução Conjunta $\mathbf{n}^{\circ} \mathbf{0 2 / 2 0 1 0}$ - SEED/SUED/DAE, de 20 de maio de 2010. Disponível em: <http://www.diaadia.pr.gov.br/sued/arquivos/File/ Instrucaoconjunta02suedsude.pdf >. Acesso em dez. 2010a.

. Parecer CP/CEE n 01/2009 - Solicita normatização para inclusão do nome social nos registros escolares do aluno, de 08 de outubro 2009. Disponível em: <http://www.cee.pr.gov.br/arquivos/File/pdf/Pareceres2009/CP/ pa_cp_01_09.pdf >. Acesso em dez. 2010b.

. Orientação Pedagógica n 01/2010 - DEDI/SEED, de 08 de novembro de 2010. Disponível em: <http://www.app.com.br/portalapp/imprensa/ orientacao_pedagogica.pdf>. Acesso em dez. 2010c.

ILGA. Campaña Stop TransPathologization 2012. Disponível em: <http://ilga. org/ilga/es/article/mBGt6B1GM >. Outubro, 2009. Acesso em dez. 2010. 